An element of incompleteness also arises, partly from the strange geographical frontiers imposed by the organization of these conferences, and partly by the fact that some nations in the region did not participate. Ten nations were directly represented, but countries in the area not directly represented were: Algeria, Afghanistan, Cyprus, Israel, Saudi Arabia, Somalia, Sudan and Yemen.

Specialized papers presented dealt with eucalyptus (Sanyer); poplar (Bersano) ; bagasse (Atchison); straw (Muller); reeds (Chivu); esparto (Grant); and cotton linters (Howell).
The published version of these papers provides, therefore, authoritative information on a wide variety of specialized aspects of the utilization of fibrous materials. Experience based on the Latin America and Tokyo sym. posia has demonstrated their value in initiating pulp and paper projects in the region concerned; and the Beirut symposium as recorded in this volume is a further example of the great value of this little-publicized activity sponsored indirectly by the United Nations Organization.

\title{
ART AND SCIENCE OF PACKAGING
}

\begin{abstract}
Tor $\mathrm{HE}$ opening of the new engineering research buildings of the Printing, Packaging and Allied Trades Research Association ('Patra') at its headquarters at Leatherhead, Surrey, on November 4, 1964, directed ronewed attention to the important work of this progressive organization. The Printing Industry Research Association, as it was first called, was formed as the result of a lecture, "Applica. tion of Science to Printing", given by Dr. G. L. Riddell in the Stationers' Hall, London, on February 8, 1929. A meeting of printing trade organizations was convened which decided to set up "a technical research bureau for the pooling of technical information and to conduct scientific investigation of technical problems". The Stationers' Company at first provided free accommodation, but in 1932 the Association moved to St. Bride's Institute. Laboratory facilities were at this time provided mainly by the London School of Printing (London County Council). By 1936 the Association was renamed the Printing and Allied Trades Research Association and became a grant-aided research unit; it was then moved to premises in Robin Hood Court, off Fleet Street, London. In 1941 these premises were completely destroyed during one of the major fire raids on London, but with generous help from several member firms the Association was re-housed in temporary accommodation in various parts of London and the Home Counties, and so its work continued. By 1942 the packaging problem of service equipment badly damaged on arrival in the Middle East and Far East combat areas had arisen, and with the co-operation of the Department of Scientific and Industrial Research, manufacturers and users of packages, and with an increased grant, the Packaging Division was formed in 1943. This expansion virtually doubled the Association"s income, and thus the foundations of the larger organization, as we now know it, were laid and its future was fully secured. Leatherhead has for many years been
\end{abstract}

a favoured locality for research associations sponsored by industry; this Association moved into new laboratories there in 1948. But within ten years enlarged premises were required and a new wing was added (opened in 1959) to accommodate the Packaging Division. The latest extension, built in 1963 to house the new engineering research buildings, brings the total floor area available at this centre to 42,000 square feet. This growth record in 35 years is one of which the Association may be justly proud. Apart from fundamental research projects based on problems in both printing and packaging techniques, 'Patra' has established some important routine day-today technical services, among which are printing enquiries, critical appraisals, machine testing, air-conditioning, high-speed camera service, package testing and advisory service, library, abstracting and translation facilities.

The work of the Association, particularly in the modern field of packaging, has been quite outstanding, although perhaps not as well known as it should be. In this connexion, the division concerned ". . . assesses products for packaging, recommends methods, materials and containers, tells where to obtain supplies, advises on specifications, tests materials or packs, indicates the standard of package performance and guards against over-packaging by ensuring economic pack design". The package testing laboratory is fully equipped for what in other industries are generally known as 'accelerated breakdown or weathering tests'; both mechanical and climatic hazards that a package may meet in transit can bo simulated in a varioty of apparatus and specially constructed environments; the scope includes tests applicable to standards of packages and packaging materials recommended in British and American Society for Testing Materials Standards, and in United States and British Government specifications.

\section{GALACTIC FLARES AND QUASI-STELLAR RADIO SOURCES}

\author{
By Prof. P. A. STURROCK
}

Institute for Plasma Research, Stanford University, Stanford, California

\begin{abstract}
A $\mathrm{T}$ the present time there is considerable interest in $A$ explosions which occur in objects of galactic dimensions. Oort ${ }^{1}$ has suggested that such an explosion has occurred in the nucleus of our own Galaxy, and there is convincing evidence of such explosions in certain galaxies ${ }^{2}$ which are strong radio emitters, and also in the quasistellar objects associated with certain very strong radio sources $^{3}$. In such an explosion, a great quantity of energy is suddenly released in the form of relativistic electrons (which produce radio and optical synchrotron radiation), kinetic energy of ejected gas clouds, and possibly other forms. This energy can be so large that it is at present believed that, for the very strong radio sources at least, it must be derived from gravitational energy ${ }^{4,5}$. The mechanism for release of gravitational energy which has been mostly widely investigated is that of 'gravitational
\end{abstract}

collapse'6-8. However, this theory does not yet give a convincing interpretation of the phenomena it sets out to explain. Gravitational collapse is a runaway process, whereas there is evidence that explosions can recur', indicating that one needs an instability. Moreover, the complicated theories of gravitational collapse have not been integrated into a larger theory showing how the initial conditions of the theory come about, and how the theoretical consequences lead to the observed characteristics of exploding galactic objects-such as strong radio emission. This suggests that alternative processes should be sought for the release of gravitational energy, and it is the purpose of this article to propose one.

Data concerning galactic explosions suggested the following requirements: (1) it should be possible for the mechanism to occur over a wide range of energy; (2) the 